\title{
Malária ocular: estudo histopatológico experimental das alterações coriorretinianas
}

Ocular malaria: experimental histopathological study of choroidal and retinal changes

\author{
Paulo Roberto de Magalhães Silva ${ }^{1}$ \\ Kátia Luz Torres Silva ${ }^{2}$ \\ Paiva Gonçalves Filho ${ }^{3}$ \\ José Fernando Barandas ${ }^{4}$ \\ Gerson Cotta Pereira ${ }^{5}$
}

\section{R E S U M O}

Objetivo: Realizar análise histopatológica dos tecidos uveal e retiniano em modelo murino que fortemente se assemelha ao desenvolvimento de malária cerebral humana, correlacionando as alterações oculares com achados encontrados em órgãos-alvo como o cérebro. Métodos: Utilizamos camundongos de linhagem isogênica $\mathrm{CBA} / \mathrm{J}$ por desenvolverem malária e evoluírem para forma grave ou cerebral quando inoculados com Plasmodium berghei (ANKA). Foi realizada inoculação via intraperitoneal e a parasitemia obtida diariamente. Para correlacionarmos as alterações com a evolução da malária, os camundongos foram sacrificados no 3ำ 7 으 e 9o dia de infecção. Após a enucleação, o globo ocular foi fixado em solução de Bouin e incluído em parafina. Os cortes foram corados com hematoxilina-eosina, tricrômica de Gomori e Giemsa. Resultados: Foram observados acúmulos de pigmentos maláricos (hemozoína) em diversas estruturas oculares, na fase inicial da doença, até alterações endoteliais de vasos retinianos, adesão de monócitos na parede vascular e congestão do lúmen vascular por hemácias parasitadas (seqüestro) em tecido uveal na fase tardia da infecção. Os níveis de parasitemia mostraram curva ascendente e significativa por volta do sétimo dia. Neste modelo observamos alterações semelhantes àquelas encontradas em outros órgãos-alvo como o cérebro. Conclusões: O modelo de malária murina permite a correlação dos achados oculares com outros órgãos-alvo da infecção. O seqüestro de células vermelhas parasitadas, na fase tardia, é responsável pela maioria das alterações oculares da malária, provavelmente com base nos fenômenos obstrutivos similares aos processos que envolvem o sistema nervoso central.

Descritores:Malária/complicações;Malária/induzidoquimicamente;Maláriacerebral; Plasmodium berghei/isolamento\& purificação;Olho/fisiopatologia;Hemorragia retiniana/ etiologia; Doenças retinianas; Infecções oculares parasitárias; Camundongos

I N T R O D U Ç ̃̃ O

Dentre as protozoonoses distribuídas mundialmente, a malária ou paludismo é a de maior incidência, atingindo um número significativo de 300 a 500 milhões de pessoas por ano em cerca de 90 países ${ }^{(1)}$. No Brasil, segundo dados da Fundação Nacional de Saúde, em 1993 foram registrados cerca de 500 mil casos, a maioria absoluta (em torno de $99 \%$ ) restrita à Amazônia Legal ${ }^{(2)}$.

A malária é causada por protozoários do gênero Plasmodium. Existem cerca de 120 espécies descritas, porém apenas 4 infectam o homem: $P$. falciparum, $P$. vivax, $P$. malariae e $P$. ovale; dentre elas, as 3 primeiras são encontradas no Brasil, com predomínio das infecções por $P$. vivax $e P$. falciparum. 
O quadro clínico da infecção palúdica pode evoluir com surtos de manifestações agudas e autolimitadas, porém, em alguns casos, apresentar-se como doença grave e de êxito letal, como ocorre na malária cerebral, dependendo da espécie de plasmódio envolvida e da resposta imunológica do hospedeiro.

$\mathrm{O}$ acometimento ocular oriundo da infecção palúdica ainda é pouco reportado, principalmente em nosso país, apesar de apresentar estreita relação com a forma grave da doença, mais precisamente a forma cerebral.

As manifestações oculares decorrentes da malária vão desde achados mais raros, como amaurose malárica, nevralgia do trigêmeo, ceratite por Herpes simplex, paralisia do oculomotor, cegueira cortical ou danos cerebrais com conseqüente acometimento ocular ${ }^{(3-4)}$ até alterações mais freqüentes como hemorragias retinianas, edema de papila e exsudatos algodonosos ${ }^{(5-9)}$.

A hemorragia retiniana é um sinal ocular freqüente, embora negligenciado, de prognóstico significativo da malária por $P$. falciparum, inclusive serve como indicativo do desenvolvimento de malária cerebral ${ }^{(9)}$.

Indivíduos com hemorragias retinianas grandes e lesões centrais parecem associar-se mais comumente a resultados pobres na evolução da doença quando comparados àqueles portadores de hemorragias periféricas observadas em casos não complicados ${ }^{(10)}$. Alguns autores afirmam que a severidade das hemorragias retinianas está relacionada com as hemorragias cerebrais ${ }^{(11)}$.

Em pacientes portadores de malária, a presença de edema macular, edema extramacular e anormalidades vasculares são consideradas variáveis preditivas do processo evolutivo da doença, isto é, sinais significativos de prognóstico para a malária grave ${ }^{(12)}$.

Os vasos retinianos podem refletir alterações vasculares patológicas decorrentes de inúmeras doenças sistêmicas, ao mesmo tempo em que podemos considerar a retina como uma extensão do córtex cerebral.

Devido a grande importância do estudo histopatológico seqüencial, ou seja, correlação dos achados histopatológicos com o tempo de evolução da infecção, utilizaremos como modelo experimental camundongos da linhagem isogênica $\mathrm{CBA} / \mathrm{J}$ devido a sua alta susceptibilidade e mortalidade por malária cerebral quando inoculados com Plasmodium berghei cepa ANKA ${ }^{(13-15)}$.

Diante desses dados nos propomos a: i) realizar uma análise histopatológica seqüencial das estruturas oculares definindo os achados coriorretinianos na infecção inicial e as alterações mais tardias decorrentes da infecção grave; ii) correlacionar as alterações oculares histopatológicas no decorrer da infecção murina com achados seqüenciais descritos em outros órgãos, mais precisamente o cérebro ${ }^{(13-14)}$.

\section{MÉ T ODOS}

\section{1) Animais e Casuística:}

Os camundongos da linhagem isogênica CBA/J foram cedidos pelo Biotério Central da Fundação Oswaldo Cruz - RJ.
Devido à alta mortalidade foram utilizados 25 camundongos, todos machos com idade de 6 semanas no momento da inoculação. Os camundongos foram divididos aleatoriamente em grupos de 6 animais por gaiola (sendo um controle e cinco infectados) mantidos nas mesmas condições de alimentação e temperatura.

\section{2) Parasita e inoculação experimental:}

As amostras do P. berghei cepa ANKA foram cedidas pelo Laboratório de Pesquisas em Malária do Instituto Oswaldo Cruz - FioCruz - Rio de Janeiro - RJ, onde se encontravam criopreservadas em nitrogênio líquido. As amostras foram descongeladas à temperatura ambiente, sendo adicionado de imediato, solução salina (cloreto de sódio $0,85 \%$ em água destilada). Procedeu-se uma centrifugação a $400 \mathrm{~g}$ por cinco minutos em temperatura ambiente. As hemácias foram lavadas com solução salina até que não houvesse mais sinal de hemólise, e posteriormente, ressuspensas, também em solução salina, até o volume desejado.

Para a manutenção da cepa in vivo foi inoculado $0,2 \mathrm{ml}$ da suspensão obtida, via intraperitoneal em camundongos que não fizeram parte do grupo experimental. Três passagens da cepa (retirada de sangue de camundongo infectado e inoculação em camundongo não infectado) foram realizadas, sempre com o acompanhamento da parasitemia.

Antes da inoculação no grupo de camundongos do experimento fez-se a contagem hematimétrica, em câmara de Neubauer, do sangue dos camundongos que mantiveram a cepa. A partir destes valores, calculou-se a diluição do sangue necessária para que um inóculo de $0,2 \mathrm{ml}$ contivesse $10^{6}$ hemácias parasitadas.

A inoculação foi realizada por via intraperitonial em cada camundongo do grupo experimental.

\section{3) Determinação da parasitemia:}

A determinação da parasitemia foi obtida através da confecção de esfregaços sanguíneos e visualização em microscopia óptica (aumento de $1000 \mathrm{x}$ ). O sangue foi coletado a partir de uma incisão na extremidade da cauda dos animais. O esfregaço foi fixado com metanol e corado pelo método de Giemsa. Posteriormente, as lâminas foram lavadas em água corrente e secadas à temperatura ambiente.

A parasitemia foi determinada pelo percentual de hemácias parasitadas em relação ao total de hemácias examinadas.

\section{4) Técnica de enucleação:}

Utilizamos 2 camundongos para padronização da técnica de enucleação.

Os camundongos foram colocados em uma câmara contendo gaze embebida com éter até que atingissem o nível de inconsciência, e posteriormente retirados da câmara e fixados em uma placa de cortiça em decúbito ventral. O procedimento de retirada do globo ocular foi realizado através de visualização em microscópio experimental, modelo Zeiss.

\section{5) Histologia:}

O material foi fixado em solução de Bouin por um período mínimo de nove horas. Posteriormente, o material foi submetido a três lavagens consecutivas com álcool etílico a 70\%, com 
intervalos de uma hora. Seguiu-se a inclusão em blocos de parafina para que se procedessem aos cortes histológicos. $\mathrm{O}$ corte do globo ocular foi feito no plano horizontal (pupila nervo óptico).

Os métodos de coloração foram Hematoxilina-Eosina, Coloração Tricrômica de Gomori (visualização de matriz extracelular) e Giemsa (observação de parasitas). A análise dos cortes histológicos foi através de microscopia óptica em aumentos 100,400 e $1000 \mathrm{x}$.

RES U L T ADOS

O primeiro grupo de animais foi sacrificado no 3 ㅇ dia de infecção. As parasitemias obtidas encontravam-se entre $1 \mathrm{e}$ $4 \%$. Nos cortes histológicos foram observados acúmulos de pigmentos maláricos localizados na camada de células ganglionares e dentro de vasos da camada nuclear externa da retina e vasos coroideanos. Observou-se também, alteração do padrão de coloração (intensidade) das hemácias quando coradas pelo método da hematoxilina/ eosina.

No 6 o dia de infecção foi encontrado morto um camundongo. Este, não foi utilizado para análise, uma vez que o objetivo do estudo era de se retirar o globo ocular com o camundongo inconsciente (mantendo-se a perfusão sanguínea tecidual).

O segundo grupo de animais foi sacrificado no 7으 dia (D7) de infecção. As parasitemias variaram entre 14,8 e 27,2\%. As alterações celulares encontradas foram aumento de volume, alterações morfológicas e presença de pigmentos maláricos nas hemácias (Figura 1).

Entre os dias 8 e 9 de infecção 4 camundongos foram encontrados mortos.

O terceiro grupo foi sacrificado no 9을 de infecção. Estes animais apresentavam-se com sinais clínicos de malária cerebral, tais como, apatia, caquexia, eriçamento de pelos, taquicardia, taquipnéia e paralisia, culminando com o chamado "roll over" (tendência a rolar sobre si mesmo involuntariamente) e

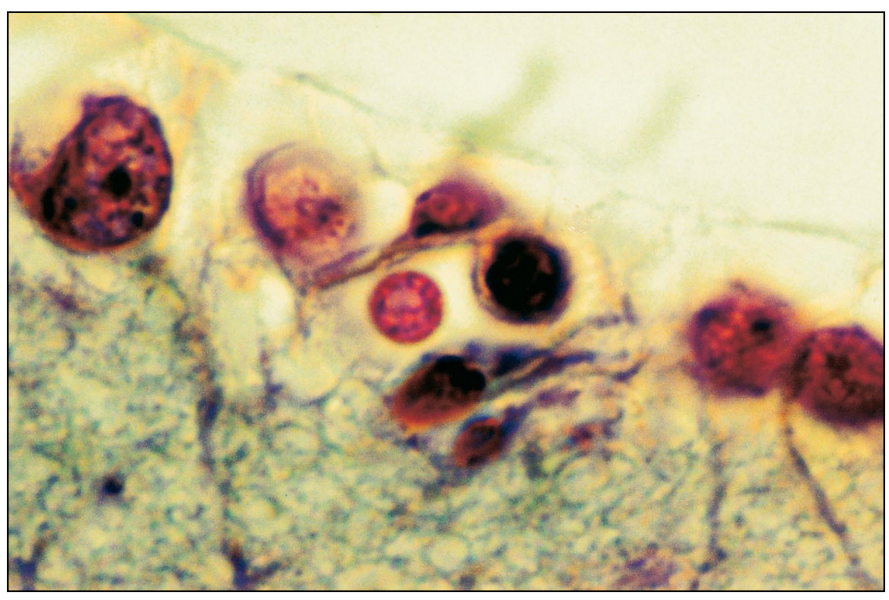

Figura 1-Hemácias com macrocitose e pigmentos maláricos coma. As parasitemias variaram entre 23 e $64 \%$, e encontradas formas de trofozoítas e esquizontes do Plasmodium berghei (Figura 2). Neste grupo de camundongos, encontramos espessamento e irregularidade do endotélio de vasos retinianos (Figura 3), acúmulo intravascular de hemácias parasitadas na retina (Figura 4) e presença de monócitos aderidos ao endotélio vascular e congestão de vasos coroideanos por hemácias parasitadas (Figuras 5 e 6).

D I S C U S S ÃO

Os níveis de parasitemia foram compatíveis com os esperados, mostrando um aumento progressivo e significativo a partir do 7o dia de infecção, o que justifica a ocorrência de óbito de alguns camundongos por volta deste período.

Os achados histopatológicos mais significativos como congestão vascular, alteração das células endoteliais dos vasos retinianos e aderência de células à parede vascular ocorreram

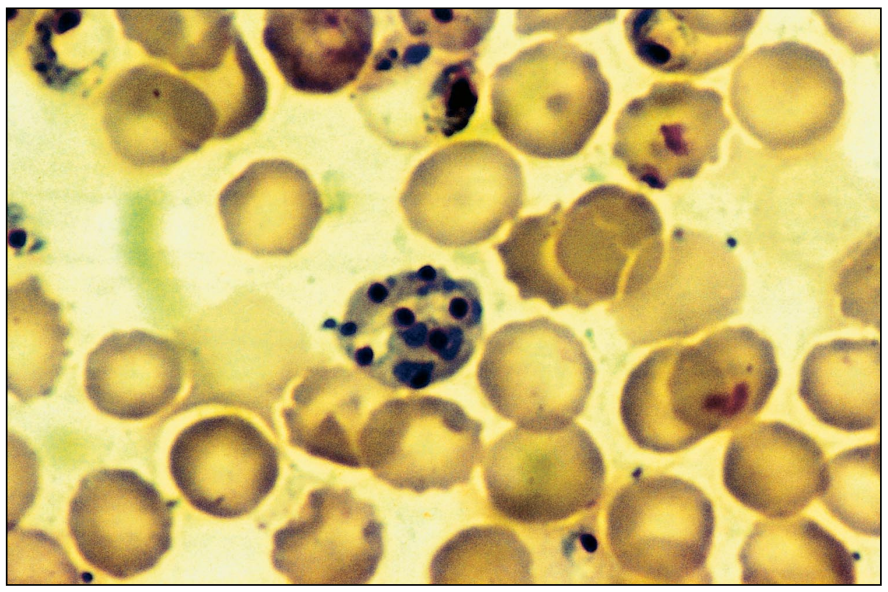

Figura 2 -Esfregaço de sangue periférico de camundongos corados em Glemsa. Presença de hemácias parasitadas

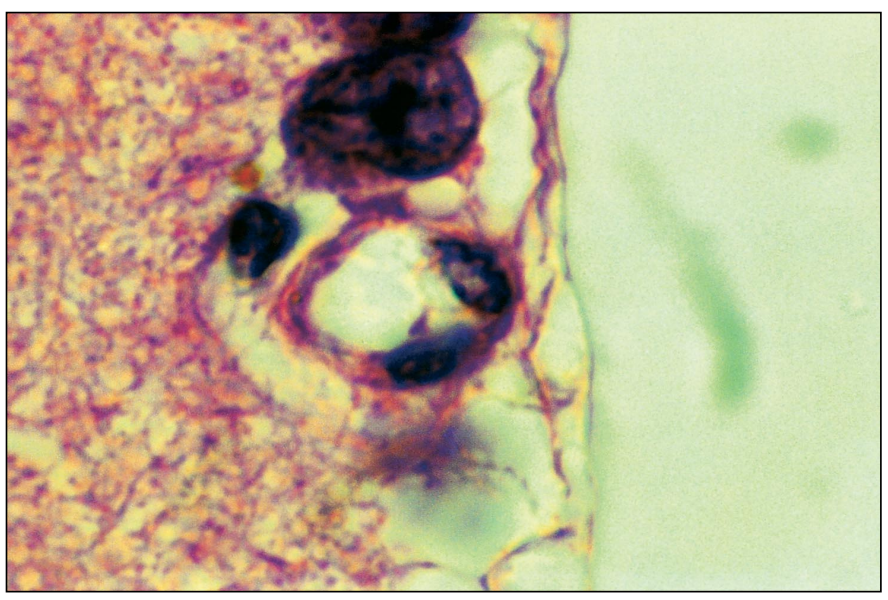

Figura3-Espessamentoeimegularidadedoendotéliodevasos retinianos. Hematoxilina/Eosina 


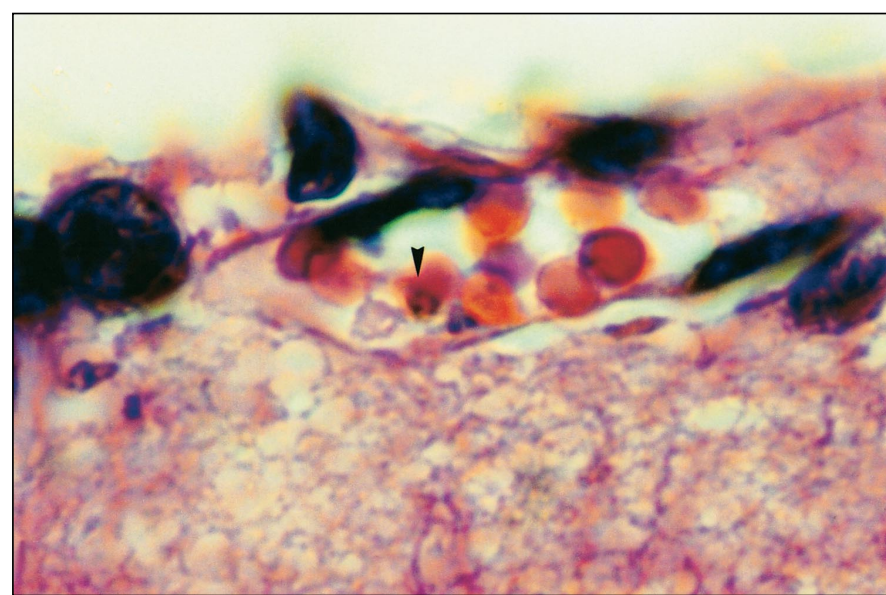

Figura4-Acúmulointravasculardehemácias parasitadas.Hematoxilina/ Eosina

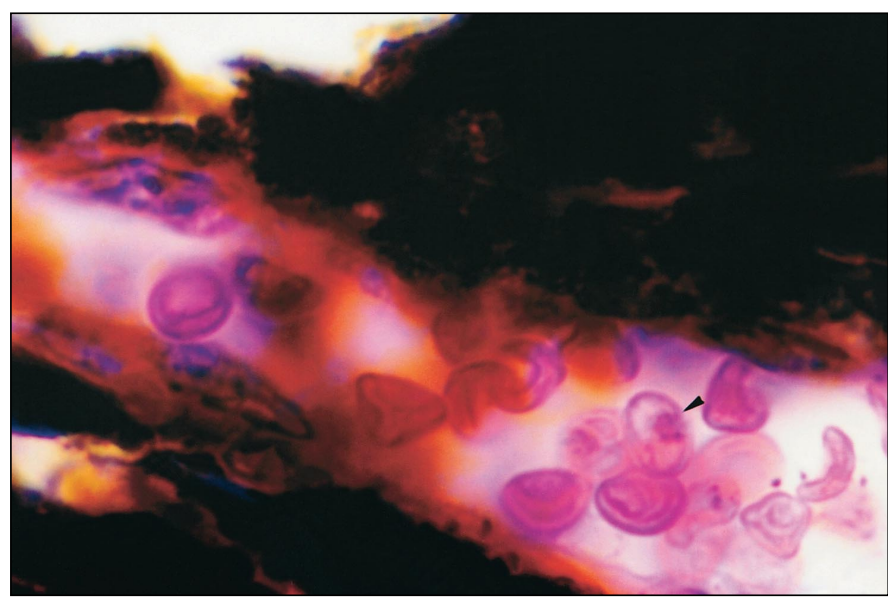

Figura5-Congestãodevasos coroideanos porhemácias parasitadas. Tricrômica de Gomori

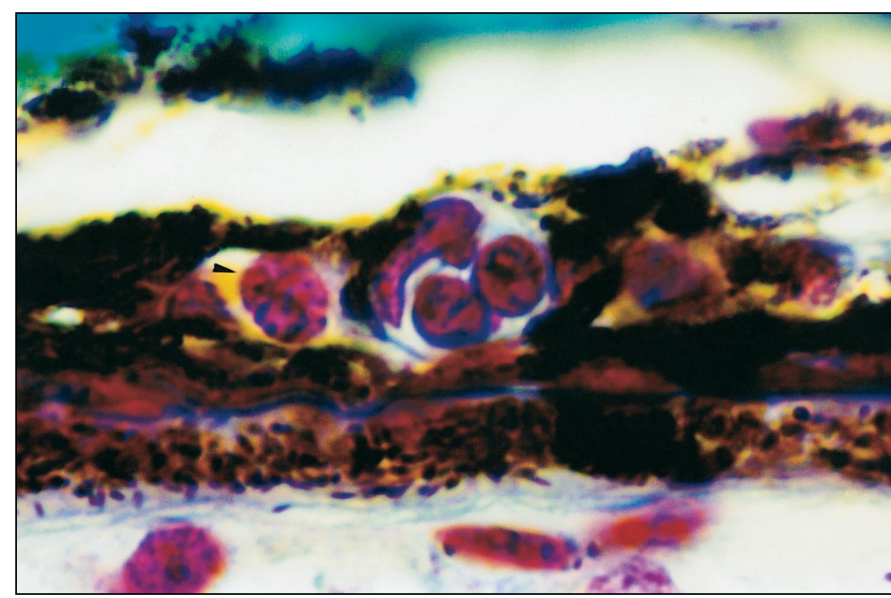

Figura 6-Congestãodevasos coroideanos porhemácias parasitadas. Tricrômica de Gomori

na presença de parasitemias mais elevadas, isto é, por volta do 9 odia de infecção. Estas alterações parecem estar diretamente relacionadas à gravidade do quadro clínico, dados estes, compatíveis com os descritos ${ }^{(11)}$.

Em outros órgãos como no cérebro, ocorre, por volta do $6^{\circ}$ dia de infecção a presença de vasos repletos de monócitos e linfócitos formando tampões intravasculares, além de extravasamento de algumas células mononucleares para o espaço perivascular que se encontra edemaciado ${ }^{(14)}$. No nosso estudo, observamos achados semelhantes porém, ao invés de tampões mononucleares, encontramos hemácias parasitadas aderidas ao endotélio vascular, conforme estudos realizados por outros autores $^{(16)}$.

As alterações oculares oriundas da infecção malárica devem estar relacionadas a lesões de células endoteliais. As hemorragias retinianas devem-se à trombose parasitária de pequenos vasos, hipóxia local e hemólise provocada pelo parasita ${ }^{(5)}$. Estas lesões podem ocorrer através de hemácias parasitadas e aderidas ao endotélio de vasos da coróide e retina, levando a obstrução parcial ou total dos mesmos, com conseqüente hipóxia e alteração na permeabilidade vascular.

Para análise dos processos de adesão celular do endotélio, faz-se necessários estudos voltados para mecanismos de citoaderência e receptores para Plasmodium nas células endoteliais de leitos vasculares coriorretinianos, por meio de técnicas imunohistoquímicas.

CONCLUSÕES

As alterações histopatológicas observadas, estão associadas a estágios mais graves da malária e podem ser consideradas como variáveis importantes na evolução da doença, pois denotam o envolvimento da microcirculação ocular na fisiopatogenia da malária.

As alterações oculares foram observadas desde o 3으 dia da infecção, porém, encontravam-se mais freqüentemente relacionadas a estados graves da doença (D7/D9), mais precisamente com a malária cerebral, o que nos leva a concluir que os fenômenos retinianos ocorram paralelamente ao comprometimento cerebral, uma vez que existe analogia entre retina e córtex cerebral.

O modelo murino utilizado proporcionou o estudo das alterações coriorretinianas desencadeadas pela infecção pelo Plasmodium berghei ANKA permitindo extrapolar evidências para a malária humana.

As alterações do fundo de olho podem anteceder o agravamento da doença, denotando dessa forma, a grande importância de um seguimento fundoscópico rigoroso em pacientes portadores de malária.

\section{A GRADECIMENTOS}

À Rosilene Gonçalves do laboratório de Pesquisas em Malária da Fundação Oswaldo Cruz - FioCruz - Rio de Janeiro, pelo apoio técnico na inoculação experimental. 
A B S T R A C T

Purpose: To accomplish a histopathological analysis of ocular structures, that is, uveal and retinal tract in a murine model that closely resembles human cerebral malaria and to correlate the ocular alterations with findings in the target organ such as the brain. Methods: We used mice of isogenic lineage (CBA/J) for they develop malaria, actually the neurological form (cerebral malaria) when inoculated with Plasmodium berghei (ANKA). We performed an intraperitoneal inoculation and parasitemia was obtained daily. To correlate the changes with malaria development, the mice were sacrificed on the $3^{\text {th }}, 7^{\text {th }}$ and $9^{\text {th }}$ day of infection. After the enucleation, the eyeball was fixed in Bouin solution for later inclusion in paraffin. The obtained sections were stained with hematoxylin and eosin, Gomori's trichrome and Giemsa. Results: Malarial pigments (hemozoyn) were observed in several ocular structures in the initial"phase of the disease, also endothelial changes in retinal vessels, monocyte adhesion and parasitized erythrocyte clogging of retinal and choroid vessels (sequestration) in the latest stage of infection. Parasitemia levels showed an ascending and critical curve by the seventh day. In this model we observed similar changes that occur in other organs, such as the brain. Conclusions: The malaria murine model permits correlation of the ocular features with those other of target organs. The sequestration of late stage parasitized red cells accounts for most ocular changes in malaria, probably on the basis of obstructive phenomena, similar to the process which involves the central nervous system.

Keywords: Malaria/complications; Malaria/chemically induced; Cerebral malaria; Plasmodium berghei/isolation \& purification; Eye/physiopathology; Retinal hemorrhage/etiology; Retinal diseases; Parasitic eye infections; Mice
REF E R E N C I A S

1. Organização Mundial da Saúde. Tratamento da malária grave e complicada: condutas práticas. Brasília; Superintendência de Campanhas de Saúde Pública; 1998. 103p.

2. Marques-Cruz A. Dados epidemiológicos de malária em todo o Brasil, referentes a 1993. Rev Soc Bras Med Trop 1995;28:141-55.

3. Roger FC. Ophthalmology in the tropics. In: Mason-Bahr, PEC, Apted, FIC. Manson's tropical diseases. $18^{\text {th }}$. ed. London: Baillère Tindall; 1982.

4. Warrel DA, Molyneux ME, Beals PF. Severe and complicated malaria. Trans R Soc Trop Med Hyg 1990;84:1-65.

5. Diallo JS. Parasitoses exotiques. In: Diallo JS. Manifestations ophtalmologiques dês parasitoses. Paris: Masson; 1985.

6. Lewallen S, Bakker H, Taylor TE, Wills BA, Courtright P, Molyneux ME. Retinal findings predictive of outcome in cerebral malaria. Trans R Soc Trop Med Hyg 1996;90:144-6.

7. Lewallen S, Harding SP, Ajewole J, Schulenburg WE, Molyneux ME, Marsh $\mathrm{K}$, et al. A review of the spectrum of clinical ocular fundus findings in $\mathrm{P}$. falciparum malaria in African children with a proposed classification and grading system. Trans R Soc Trop Med Hyg 1999;93:619-22.

8. Hearn J, Rayment N, Landon DN, Katz DR, Souza JB de. Immunopathology of cerebral malaria: morphological evidence of parasite sequestration in murine brain microvasculature. Infect Immun 2000;68:5364-76.

9. Looareesuwan S, Warrell SA, White NJ, Chanthavanich P, Warrell MJ, Chantaratherakitti S, et al. Retinal hemorrhage, a common sign of prognostic significance in cerebral malaria. Am J Trop Med Hyg 1983;32:911-91.

10. Davis TM, Suputtamongkol Y, Spencer JL, Ford S, Chienkul N, Schulenburg WE, et al. Measures of capillary permeability in acute falciparum malaria: relation to severity of infection and treatment. Clin Infect Dis 1992;15:256-66.

11. White VA, Lewallen S, Beare N, Kayira K, Carr RA, Taylor TE. Correlation of retinal haemorrhages with brain haemorrhages in children dying of cerebral malaria in Malawi. Trans R Soc Trop Med Hyg 2001;95:618-21.

12. Lewallen S, Taylor TE, Molyneux ME, Wills BA, Courtright P. Ocular fundus findings in Malawian children with cerebral malaria. Ophthalmology 1993;100:857-61.

13. Carvalho LJM. Malária murina por Plasmodium berghei ANKA: estudo imunológico e histopatológico seqüencial com ênfase em órgãos linfóides[tese]. Rio de Janeiro. Instituto Oswaldo Cruz - Fiocruz; 1995.

14. Carvalho LJ, Lenzi HL, Pelajo-Machado M, Oliveira DN, Daniel-Ribeiro CT, Ferreira-Da-Cruz MF. Plasmodium beghei: cerebral malaria in CBA mice is not clearly related to plasma TNF levels or intensity of histopathological changes. Exp Parasitol 2000;95:1-7.

15. Lou J, Lucas R, Grau GE. Pathogenesis of cerebral malaria: recent experimental data and possible applications for humans. Clin Microbiol Rev 2001; 14:810-20.

16. Newbol C, Craig A, Kyes S, Rowe A, Fernandez-Reyes D, Fagan T. Cytoadherence, pathogenesis and the infected red cell surface in Plasmodium falciparum. Int J Parasitol 1999;29:927-37.

\section{A B O E LETRÔN I C O \\ $\mathrm{N}$ ovo site}

Acesso: http://www.abonet.com.br 